\title{
Characterizing hospital pathways for the care of acquired hemophilia in France using comprehensive national health data
}

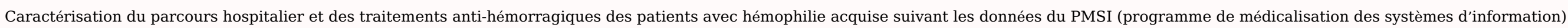

B. Guillet ${ }^{\mathrm{a}, \mathrm{b}, *}$

benoit.guillet@chu-rennes.fr

A. Aouba $^{\mathrm{c}}$

J.-Y. Borg ${ }^{\mathrm{d}, \mathrm{e}}$

J.F. Schved ${ }^{\mathrm{f}}$

H. Léves

${ }^{\mathbf{a} C e n t r e ~ d e ~ t r a i t e m e n t ~ d e s ~ m a l a d i e s ~ h e ́ m o r r a g i q u e s, ~ C H U ~ d e ~ R e n n e s, ~ R e n n e s, ~ F r a n c e ~}$

bInserm, EHESP, IRSET (institut de recherche en santé, environnement et travail) - UMR_S 1085, Université Rennes, CHU de Rennes, 35000 Rennes, France

${ }^{\mathbf{c}}$ Département de médecine interne et immunologie clinique, CHU de Caen-Normandie, Caen, France

dLaboratoire d'hématologie, Normandie Université, UNIROUEN, 76031 Rouen, France

${ }^{\mathbf{e}}$ Centre de traitement des maladies hémorragiques, Normandie Université, UNIROUEN, 76031 Rouen, France

fDépartement d’hématologie biologique, centre de traitement des maladies hémorragiques, CHU de Montpellier, Montpellier, France

9Service de médecine interne, Normandie Université, UNIROUEN, 76031 Rouen, France

${ }^{*}$ Corresponding author.

\section{Abstract}

Purpose

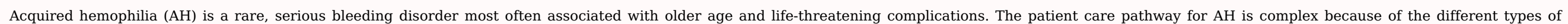
bleeding, the presence of comorbidities, and the heterogeneity of medical specialists who care for these patients.

Methods

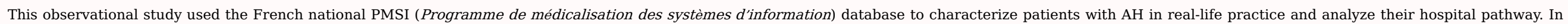

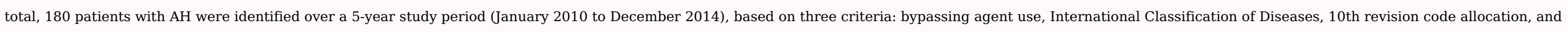
aged over 65 years. Comparison of the incidence rate of AH versus registry data validated the PMSI as an epidemiological database.

Results

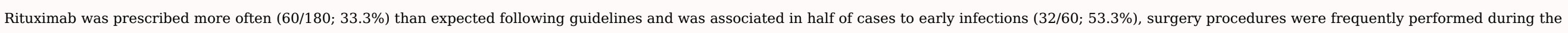

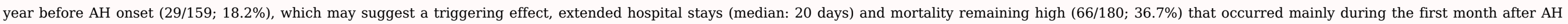
diagnosis. Median costs and number of injections were comparable between recombinant activated factor VII and plasma-derived activated prothrombin complex concentrate.

Conclusion 
Keywords: Antibodies; Chronic disease; Epidemiology; Factor VII; Hemophilia; Public health

\section{Introduction}

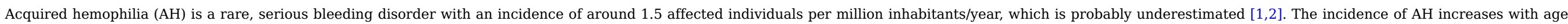

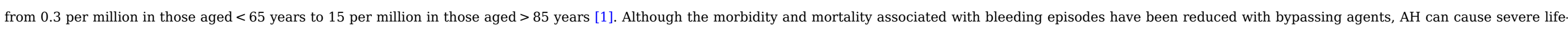
threatening bleeding complications [3], especially in patients aged $>76$ years [4].

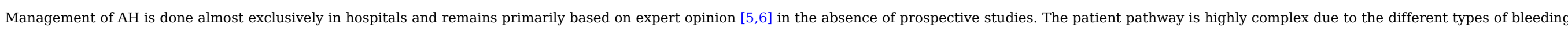

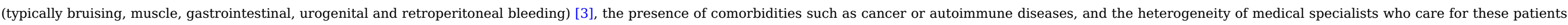
The consequence is delayed diagnosis and management by specialists.

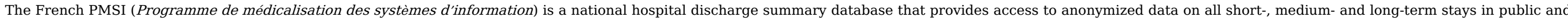

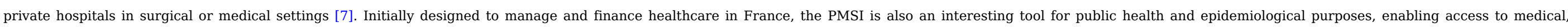
demographic, quantified and standardized data.

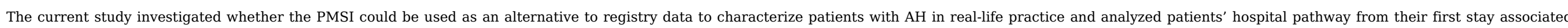
with bypassing agent use.

\section{Methods}

\subsection{PMSI}

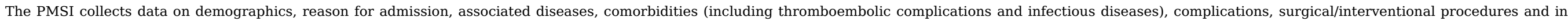

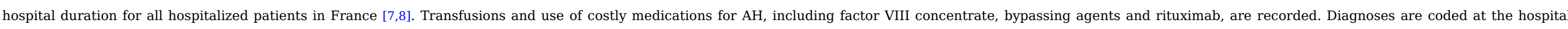

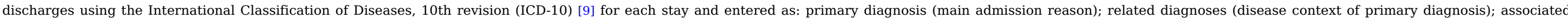
diagnoses (complications/comorbidities).

The severity of hospital stays is allocated to one of four grades according to age, primary diagnosis, comorbidities and general patient status $(1=$ lowest severity; $4=$ highest severity).

\subsection{Patient selection}

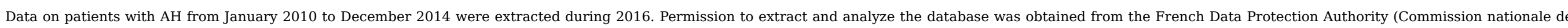
l'informatique et des libertés [CNIL]).

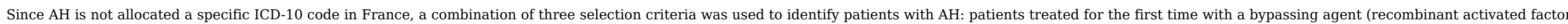

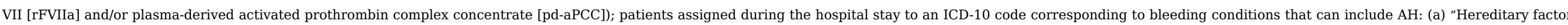

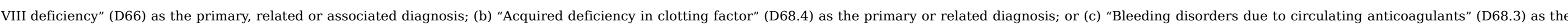

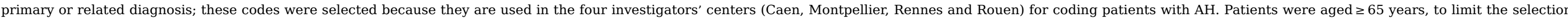
of patients with inherited bleeding conditions and to better target the elderly AH demographic.

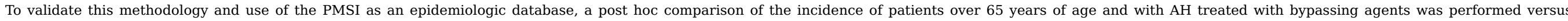

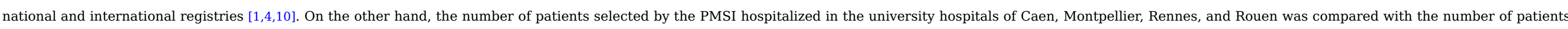
who had a confirmed diagnosis of AH by the Bethesda titration method in the same university hospitals and during the same period. 


\subsection{Data collection}

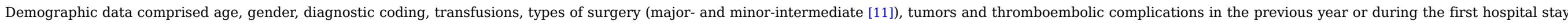
for $\mathrm{AH}$, and comorbidities such as autoimmune diseases preceding/during the first hospital stay.

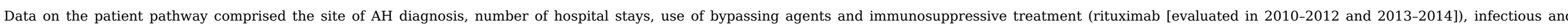
thrombotic complications and mortality (Online material Supplemental Table)

\subsection{Data analysis}

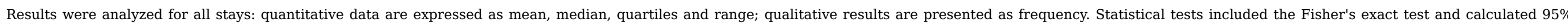
confidence intervals (CIs)

\section{Results}

\subsection{Patient population}

In total, 180 patients with AH were identified during the 5-year study period (Table 1). Overall median patient age was 82 years (range, 65-100 years) (Fig. 1).

Table 1 Distribution of $I C D-10$ diagnostic codes at initial diagnosis.

alt-text: Table 1

Diagnostic codes

Total patients

Patients with only one code (151/180, 84\%)$$
\text { D66 }
$$

(Female/male)

D68.3

D68.4

Patients with associated codes $(29 / 180,16 \%)$

D68.3 + D68.4

$\mathrm{D} 66+\mathrm{D} 68.3$

$\mathrm{D} 66+\mathrm{D} 68.4$

D66 + D68.3 + D68.4
180

68

$(30 / 38)$

18

65
100

37.8

(44.1/55.9)

10.0

36.1

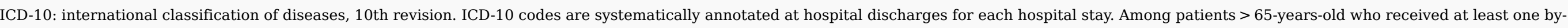

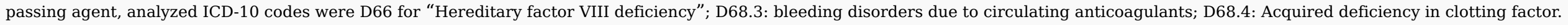




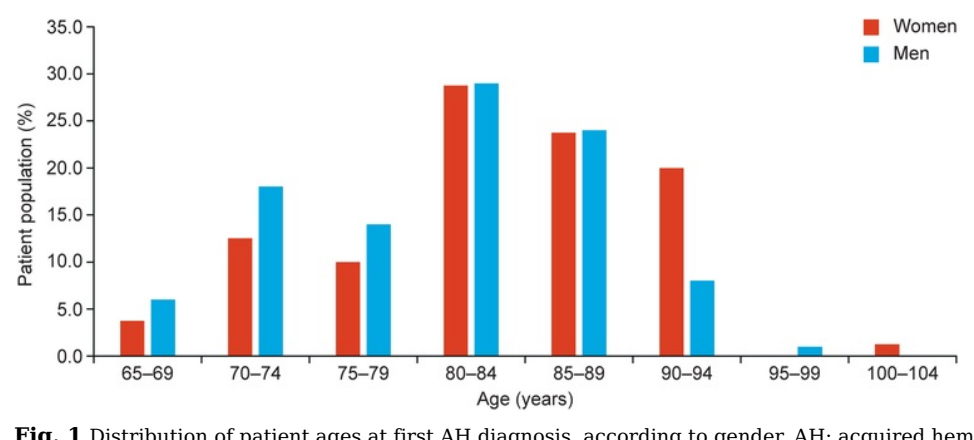

Fig. 1 Distribution of patient ages at first AH diagnosis, according to gender. AH: acquired hemophilia.

\subsection{Confirmation of methodology}

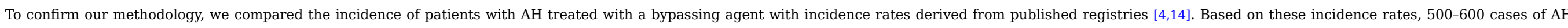

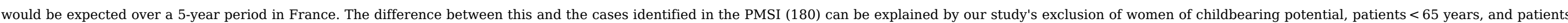

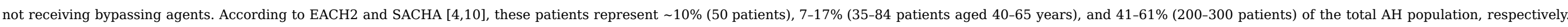

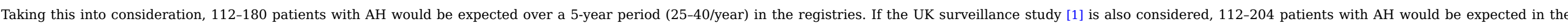

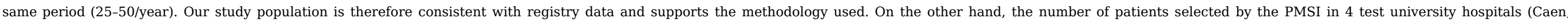
Montpellier, Rennes and Rouen) was the same as that of diagnosed patients in same the hospitals and during the same period.

\subsection{Sites of AH diagnosis}

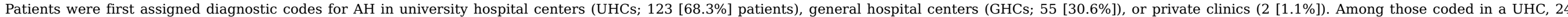

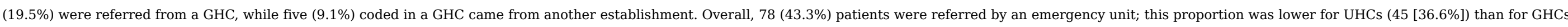
(33 [60.0\%]), suggesting that direct entry to a specialized department for diagnosis occurred more frequently at UHCs than GHCs.

\subsection{Number of hospital stays}

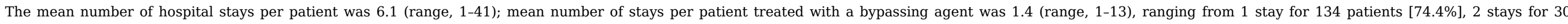
[16.7\%], 3 stays for $11[6.1 \%])$ and $\geq 4$ stays for five [3\%].

\subsection{Comorbidities}

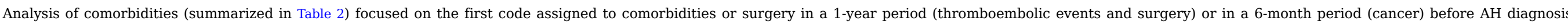

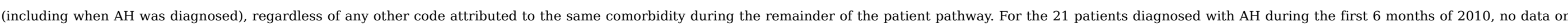

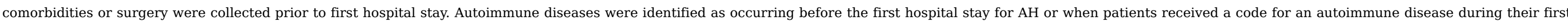
stay.

Table 2 Comorbidities, surgeries and thrombotic events before or at the time of the acquired hemophilia diagnosis.

alt-text: Table 2 


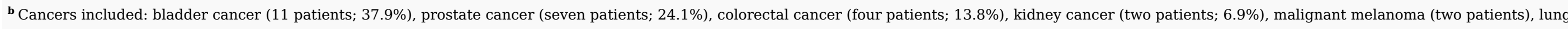

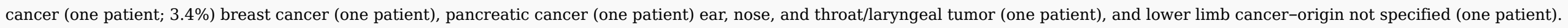

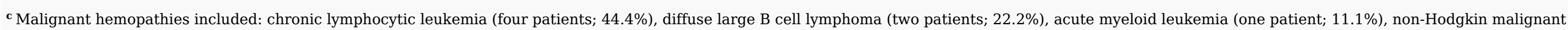
lymphoma (one patient) and one unspecified malignant immune proliferative disease.

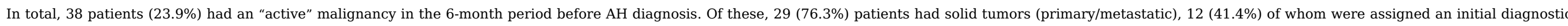

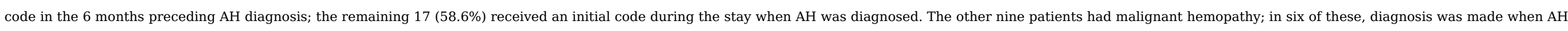
was diagnosed. Eleven (6.1\%) in total had autoimmune diseases, rheumatoid arthritis being the most common (7/11 patients, 63.6\%).

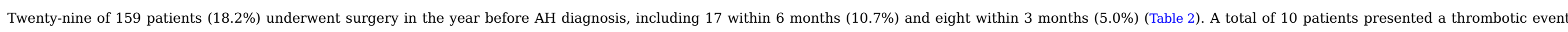
during the year before or during the AH diagnosis.

\subsection{Transfusions}

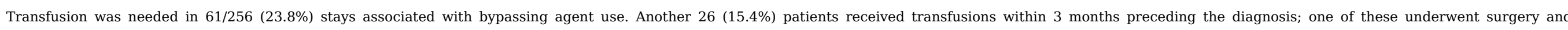
transfusion during the same stay.

\subsection{Severity of hospital stays associated with bypassing agents}

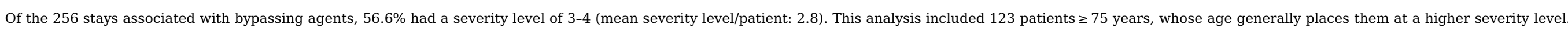
However, even among patients aged 65-74 years $(n=35)$, 38.0\% of hospital stays with bypassing agents were allocated a severity level of 3-4 (mean severity level/patient: 2.4 ).

\subsection{Bypassing treatments}

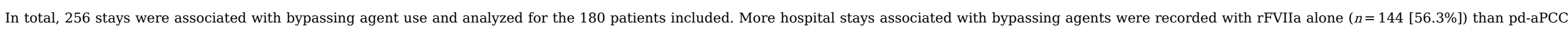
alone (84 [32.8\%]); both bypassing agents were used during the same stay on 16 (6.3\%) occasions (Table 3). Twelve stays (4.7\%) were managed with both FVIII and one bypassing agent. 
Table 3 Number and duration of hospital stays for acquired hemophilia associated with bypassing agents treatments.

alt-text: Table 3

\begin{tabular}{|c|c|c|c|c|}
\hline & rFVIIa as monotherapy & pd-aPCC as monotherapy & rFVIIa + pd-aPCC during same stay & Total \\
\hline Total number of first stays with AH diagnosis & 104 & 65 & 11 & 180 \\
\hline Total number of stays for $\mathrm{AH}$ & 149 & 91 & 16 & 256 \\
\hline \multicolumn{5}{|l|}{ Duration of stays, days } \\
\hline Mean (SD) & $20.4(16.1)$ & $26.4(19.5)$ & $42.4(19.3)$ & $23.9(18.4)$ \\
\hline $\begin{array}{l}\text { Median } \\
(\mathrm{Q} 1-3)[\text { Min-max] }\end{array}$ & $\begin{array}{l}17.5 \\
(8-27)[0.5-83]\end{array}$ & $\begin{array}{l}23 \\
(13-35)[0.5-112]\end{array}$ & $\begin{array}{l}41 \\
(29-53) \text { [14-73] }\end{array}$ & $\begin{array}{l}20 \\
(11-32)[0.5-112]\end{array}$ \\
\hline
\end{tabular}

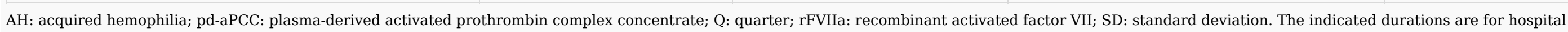

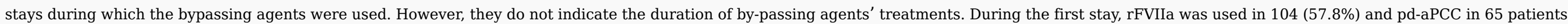

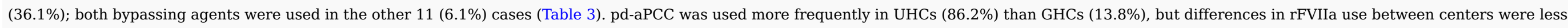

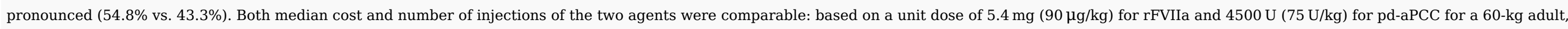
the estimated median number of injections/patient was 6.6 for rFVIIa and 6.4 for pd-aPCC. Table 4 summarizes the bypassing agents' dosages.

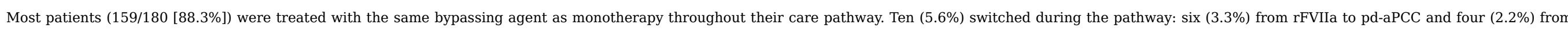
pd-aPCC to rFVIIa. Eleven received both bypassing agents during the same hospital stay; of these, only one required another stay, when he received rFVIIa.

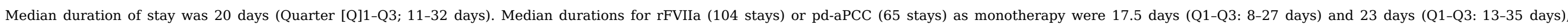

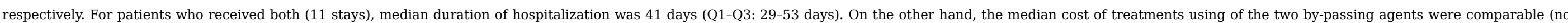
significant difference) (Table 4).

Table 4 Consumption of bypassing agents during all the hospital stays.

\section{alt-text: Table 4}

\begin{tabular}{|c|c|c|c|c|}
\hline & rFVIIa & pd-aPCC & rFVIIa & pd-aPCC \\
\hline & \multicolumn{2}{|c|}{ As monotherapy } & \multicolumn{2}{|c|}{ With the 2 bypassing agents during the same stay } \\
\hline \multicolumn{5}{|l|}{ Dosages per stay } \\
\hline Total & $19,944 \mathrm{mg}$ & $4725.50 \mathrm{kU}$ & $4397 \mathrm{mg}$ & $1461.5 \mathrm{kU}$ \\
\hline Mean (SD) & $133.8 \mathrm{mg}(211.7)$ & $51.93 \mathrm{kU}(64.67)$ & $274.8 \mathrm{mg}(281.5)$ & $91.34 \mathrm{kU}(72.35)$ \\
\hline $\begin{array}{l}\text { Median } \\
\text { (Q1-Q3) [Min-max] }\end{array}$ & $\begin{array}{l}36 \mathrm{mg} \\
(14-158)[1-1262]\end{array}$ & $\begin{array}{l}29 \mathrm{kU} \\
(10-69)[1-435]\end{array}$ & $\begin{array}{l}147 \mathrm{mg} \\
(87-457) \text { [17-844] }\end{array}$ & $\begin{array}{l}77.50 \mathrm{kU} \\
(43.75-122.00)[5-243]\end{array}$ \\
\hline \multicolumn{5}{|l|}{ Costa per stay, k€ } \\
\hline $\begin{array}{l}\text { Median } \\
\text { (Q1-Q3) }\end{array}$ & $\begin{array}{l}20.25 \\
(7.88-88.86)\end{array}$ & $\begin{array}{l}24.22 \\
(8.40-57.62)\end{array}$ & 159.28 & \\
\hline
\end{tabular}

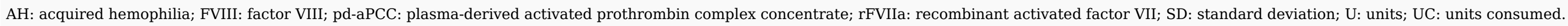

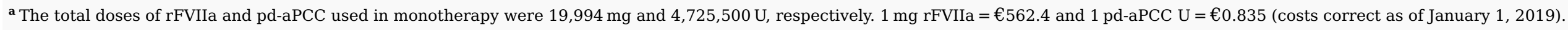

\subsection{Thrombotic complications post-diagnosis}




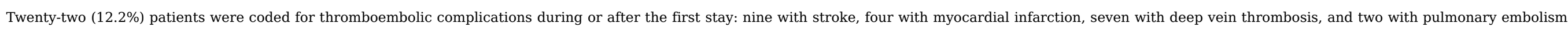
None had a history of thromboembolic disease in the 12 months before AH diagnosis.

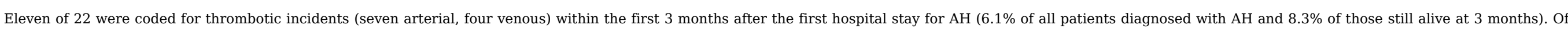

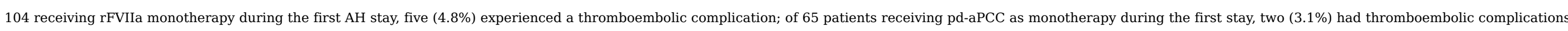
(a non-significant difference).

\subsection{Mortality}

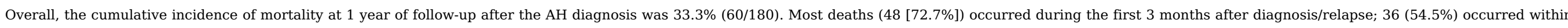

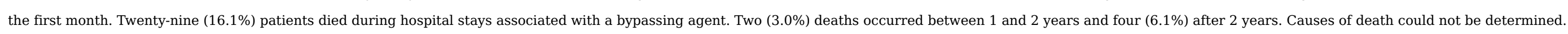

\subsection{Rituximab use}

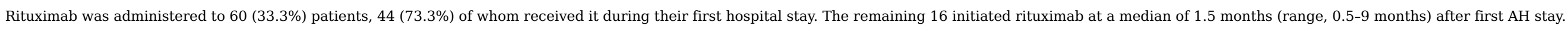

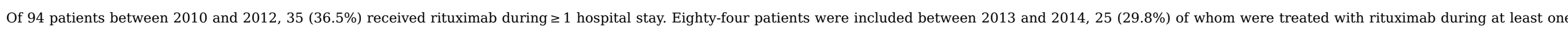

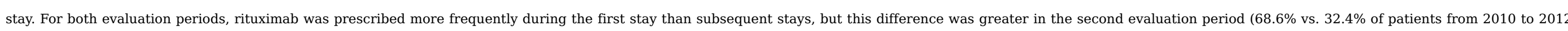
and $80.0 \%$ vs. $20.0 \%$ from 2013 to 2014 ).

\subsection{Infectious complications}

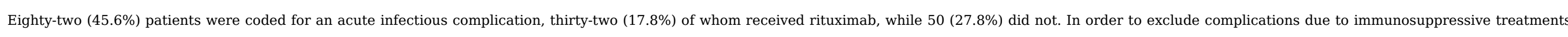

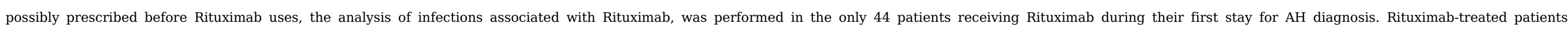
experienced more infections in the 6 months after the first injection (20/44 [45.5\%]) than those who did never receive rituximab (34/120 [28.3\%]; odds ratio 2.11 [95\% CI: 1.03-4.31]; $P=0.04)$.

\section{Discussion}

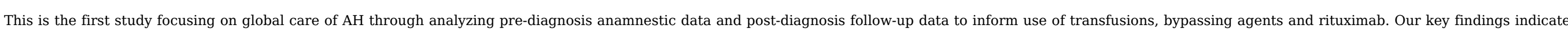

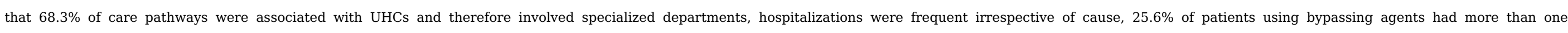
hospitalization, $56.6 \%$ of stays with bypassing agents had a severity level of 3-4 and infectious complications were probably underestimated.

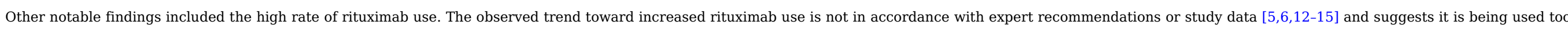

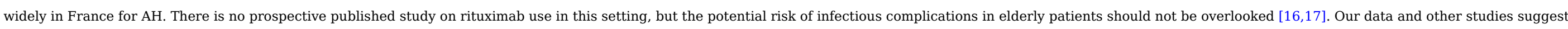

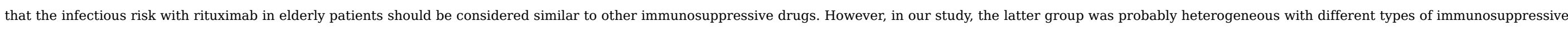

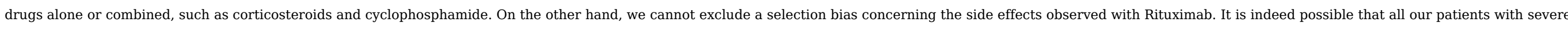

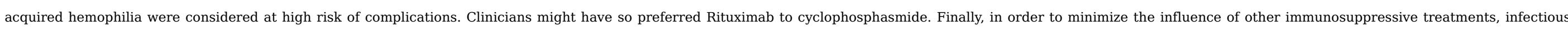

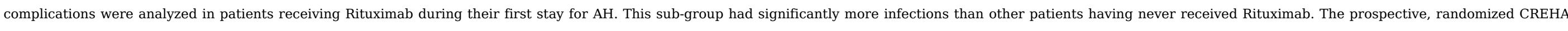

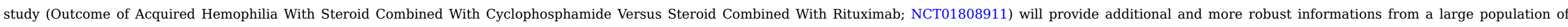
patients with AH.

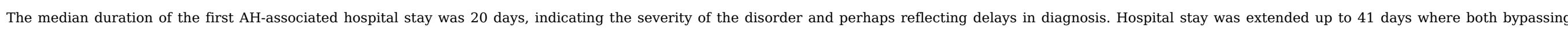

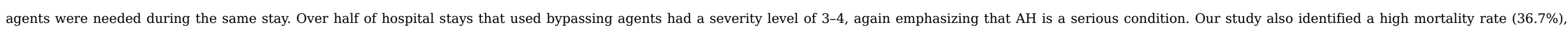

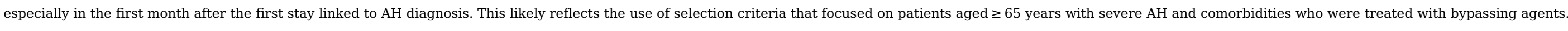

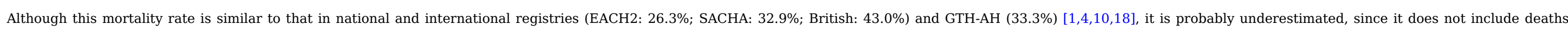
occurring outside public/private hospitals. 


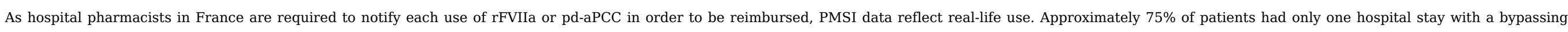

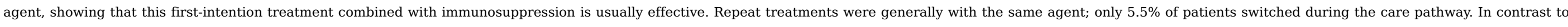
previous reports $[4,10]$, both median cost and number of injections of the two bypassing agents were comparable.

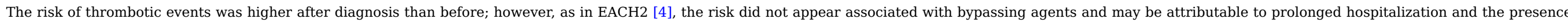

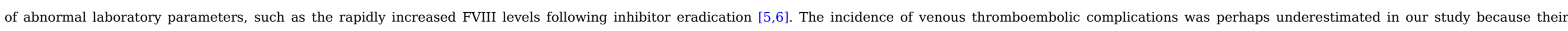
treatment does not necessarily require hospitalization.

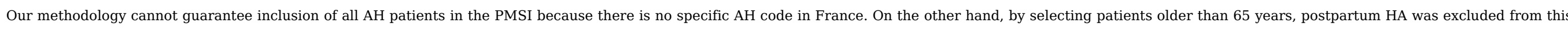

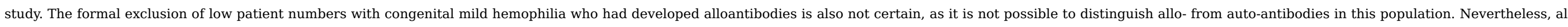

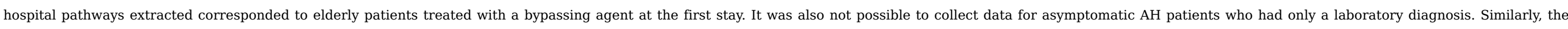

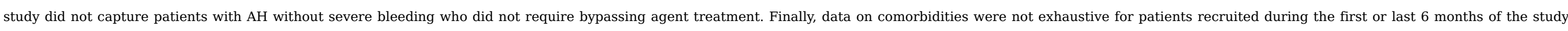
period.

\section{Conclusions}

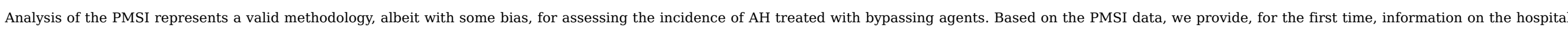

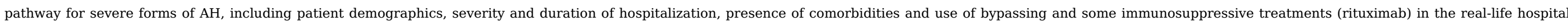
setting. These findings could inform future medico-economic approaches in this population (duration of stays, bypassing agents, rituximab use, comorbidities, hospitalizations with infections).

\section{Funding}

Funding for this project was provided by Novo Nordisk A/S.

\section{Disclosure of interest}

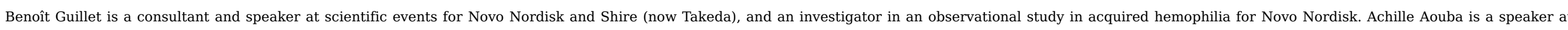

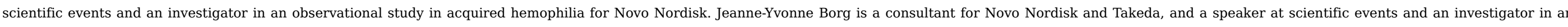

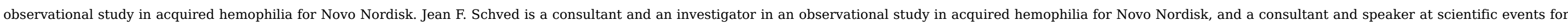

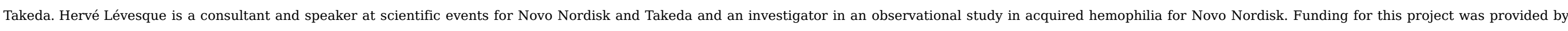
Novo Nordisk A/S.

\section{Acknowledgments}

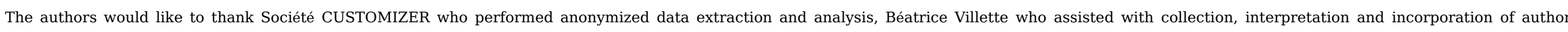

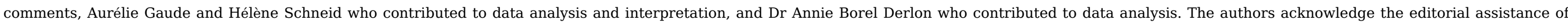
Jessica Beishon and Caroline Cook (Parexel).

\section{Appendix A. Supplementary data}

Supplementary data associated with this article can be found, in the online version, at https://doi.org/10.1016/j.revmed.2021.07.003.

\section{References}

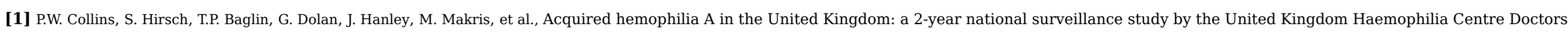
Organisation, Blood 109 (5), 2007, 1870-1877.

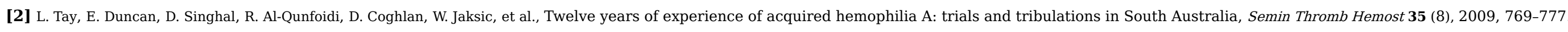




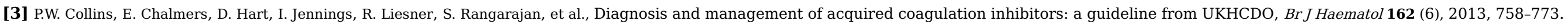

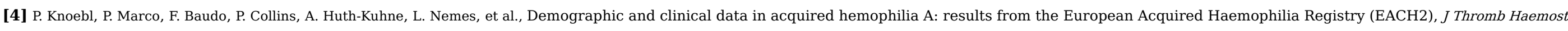
10 (4), 2012, 622-631.

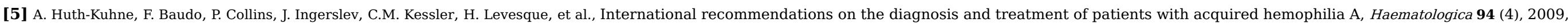
566-575.

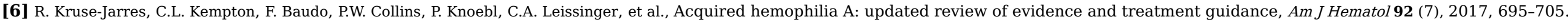

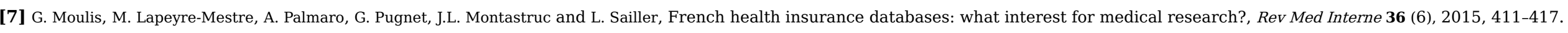

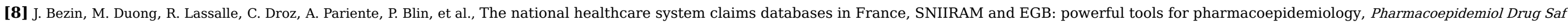
26 (8), 2017, 954-962.

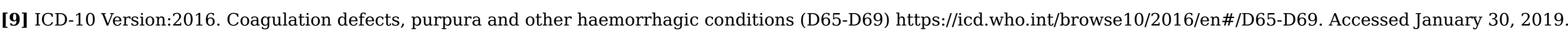

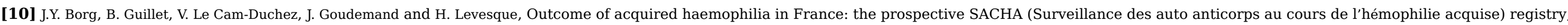
Haemophilia 19 (4), 2013, 564-570.

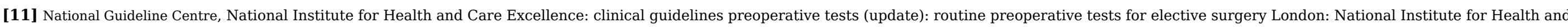
care excellence (UK). Copyright $\odot, ~ 2020$, National Institute for Health and Care Excellence.

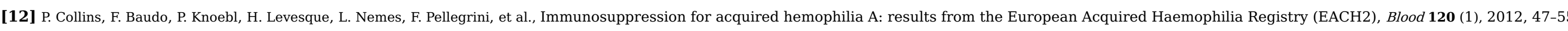

[13] P.W. Collins, Management of acquired haemophilia A, J Thromb Haemost 9 (Suppl 1), 2011, 226-235.

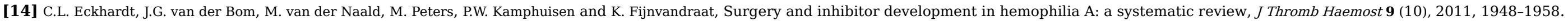

[15] M. Franchini and P.M. Mannucci, Inhibitor eradication with rituximab in haemophilia: where do we stand?, BrJ Haematol 165 (5), $2014,600-608$.

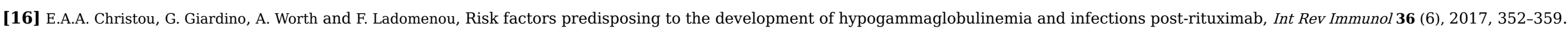

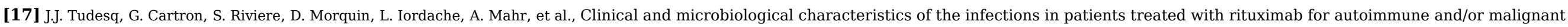
hematological disorders, Autoimmun Rev 17 (2), 2018, 115-124.

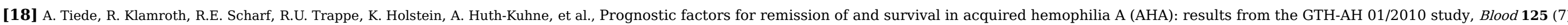
2015, 1091-1097.

\section{Online material Supplementary data}

$\underline{\text { Multimedia Component } 1}$ 